\title{
A Model for Evaluating Big Data Analytics Tools for Organisation Purposes
}

\author{
Phaphama Kangelani and Tiko Iyamu ${ }^{(\bowtie)}$ \\ Cape Peninsula University of Technology, Cape Town, South Africa \\ phaphama3@gmail.com, iyamut@cput.ac.za
}

\begin{abstract}
Big data analytics tools have many functions that are common or similar to one another. This is a problem for many organisations that are either interested or have deployed some of the tools. The problem arises because there is no mechanism on how to determine appropriateness of the tools within context in an environment. Some of the implications of the problem are that it is difficult to assess appropriateness of the tools in an environment, which sometimes result to duplication; and the value of the tools. The aim of this project was to propose a solution through a model that can be used to evaluate big data analytics tools for organisations' benefits. The qualitative method, case study approach and semi-structured interview technique were applied in the study. From the analysis, the role of criteria, business and IT alignment, governance, and skill-sets were revealed as critical factors. Based on the factors, a model was developed, which can be used as a building block through which evaluation of big data analytics tools in an organisation is carried out.
\end{abstract}

Keywords: Big data analytics $\cdot$ Evaluation $\cdot$ Criteria

\section{Introduction}

Big data is not about the size of data, but characterised by three dimensions: variety, volume and velocity [1]. Big data is processed by computerised software or applications, which is referred to as big data analytics [2]. Some of the big data analytics (BDA) tools include Hadoop, MapReduce [3]. There is increasing interest in the use of BDA from both academia and industry $[4,5]$, which can be attributed to the premise that the concept brings positive change to an environment that deploys it [6].

Organisations adopt big data concept to get some insights into the data to predict the future. Many organisations employ big data with the intention of improving activities and events such as sales, advertising, and future predictions [7]. In the process of optimising the benefits of BDA, some organisations divide it into two sections: management, which is the extraction, retrieval and storage of datasets for transformation and decision-making purposes; and as the technology tool for analysing big data [8].

Despite the benefits that BDA seem to present, there are challenges with the concept, which include violation of privacy, security, data quality, slowness in query processing, scalability problems, integration complexities, and scarcity of big data skills $[1,9,10]$. Some of the challenges persist because there has been slow or lack of 
research, theoretical constructs, and academic rigor from management and perspective, in the areas of big data and BDA [11]. At large, there has also been a lack of research studies that comprehensively addresses the key challenges of BDA, or which investigates opportunities for new theories or emerging practices. This includes evaluation of big data analytics tools [12].

The main challenge is that there are no evaluation models or methods that can be used to assess BDA tools, and research have not focused on this aspect. Because of the variation of the big data analysis tools, some organisations have a challenge in selecting the most appropriate application for analysis [13]. There are some models, but they only focus on the evaluation of $[14,15]$. As at the time of this research, the only study that focuses on evaluation of BDA tools, Hadoop, Spark, and Flink is from performance perspective [16]. This means that the gap remains, which this study aimed to address. Thus, the aim of this study was to propose a solution through a model that can be used to evaluate BDA tools in selecting the most appropriate for organisations' purposes. Thus, the objectives of this study were: (1) To determine the factors (technical and business) that influence the selection of big data analytics in organisations; and (2) To establish criteria for appropriateness of big data analytics tools in an organisation.

\section{Literature Review}

This review of literature was split into three areas in order to gain more insight on the specific areas, which are big data analytics, value of big data in organisations, and evaluation technique.

\subsection{Big Data Analytics}

The BDA approaches include predictive, descriptive and prescriptive [17]. The approaches focus on analysing unstructured, semi-structured and structured datasets, which can be images, audio or text [1]. The analysis of big data involves machine learning applications or software like Hadoop, MapReduce, Apache and many more [3].

The predictive analytics tools focuses on historical data to predict the future. The analysis makes use of machine learning algorithms and statistical models to assess historical datasets for future predictions [18]. The descriptive analytics focuses on current state, present datasets [19]. It uses historical datasets to identify patterns that can be reported or compared to current trend. The prescriptive analytics as an assessment of current situation to make decision [1]. It combines both the descriptive and predictive analytics in finding new ways to achieve positive outcomes for organisations.

The efficiency of BDA is one of the reasons that organisation adopt and use the concept as a solution to decision making [20]. Competitiveness is one of organisation's purposes in the use of BDA for predicting the future outcomes [18]. It is argued that the BDA are used to deliver predictive insights in operations, drive real-time in decision making, and redesigning of business processes, in achieving results for organisational 
goals and objectives [21]. Despite the consistent argument that the BDA has a lot to offer to organisations, many challenges have been identified in the use of the concept [3], which include data validation, data cleansing, scalability of algorithms, and parallel data processing [22].

\subsection{Value of Big Data Analytics in Organisations}

In recent years, there has been increase in the use of BDA tools, which can be attributed to the values that are associated to the concept [7]. Grover et al. suggest that the concept of BDA can be used to promote productiveness and decision-making, which brings forth to organisations [23]. Two socio-technical features, convenience and interconnectivity are identified as the factors that influence the value of BDA in organisations [24]. Some organisations are fascinated with the capabilities of the BDA in that it enable integration of data types, from different perspectives such size and variety [23].

In organisations, the value of BDA is viewed from different perspectives. One viewpoint, the value of BDA for an organisation is the process of collecting, storing and gaining insights to enhance organisation's performance [25]. From another angle, the ability to integrate, accessibility, response time are the value of the BDA in some organisations [26]. However, the BDA tools do not operate themselves, which is another challenge that is associated to the concept, and influence the type of value that is obtained. The emerging nature of the BDA makes skillsets scarce [27, 28].

\subsection{Evaluation Models and Techniques}

In the field of IS, evaluation of software is critical, due to increasing reliance on it as solution in organisations. Another rationale for evaluating software is to ensure awareness and detect deficiency [29]. Thus, many computer systems undergo evaluation process [15]. Within the computing environment, there are various models and techniques for conducting evaluation of software and approaches. One of the techniques is that the evaluation begins with measuring technology functionalities, to align with the business requirements and needs [30].

There are numerous types of evaluation models and techniques. One of the evaluation technique is a Holistic Framework on IS evaluation which consists of five evaluation factors: Strategic value, Profitability, Risk, Successful Development and Procurement, and Successful Use and Operations [31]. Another rationale for evaluation in IS field is to mitigate against risk in projects and assess effectiveness of systems in an organisation. Also, there is no limit to evaluation is that there will always be new factors to evaluate [32].

\section{Research Methodology}

Based on the objective of the study, which was to examine and understand the factors that influence big data analytics and its appropriateness, the qualitative method, case study approach were employed in the study. This means that individuals and groups 
opinions and views was sought, which the qualitative method allows. The qualitative research is mostly employed in a scientific research to collect data, find answers to questions and draw conclusion from the findings produced [33]. The focus of the qualitative method is not about numbers or statistics, it rather on human reactions such as feelings, emotions, and experiences in their real world [34]. The qualitative approach is mostly associated with subjectivism [35].

The case study approach was employed mainly because it focuses on the in-depth of the phenomenon being studied. Yin defines case study as an adaptable and openminded technique of information gathering [36]. The approach is broad, meaning a case can be an individual, an organisation, a community, a group, or an event [37]. The Plan Investments organisation was used as a case in the study. The organisation is a financial institution situated in Cape Town. It has over 150 employees at the time of this study.

Based on the level of the study, a criterion was used for a selection of participants. The criterion included the following: (1) organisation that employ big data analytics tools, and grants permission for the study; (2) participants should have be with the organisation for at least a year. Within the case study, data was collected. Participants that were interviewed included IT manager and Architects.

The semi-structured interview technique was used to collect data. This was to ensure flexibility during the process, in asking questions, which ultimately increases the chances of collecting rich data. The interviews was conducted with interviewees on one-on-one basis. The venue of the interviews was decided by the interviewees, to ensure their comfort. The interviews was tape recorded on the permission of the interviewees. In addition, notes were taken during the interviews, to increase comprehensiveness of the data collected.

The hermeneutics approach was applied in the analysis of the data, from the perspective of the interpretivist approach [38]. The hermeneutics approach proposes a method for understanding textual data [39]. The approach helps to clarify and guide an understanding of objects and subjects in an interpretive manner [40]. Interpretivist approach is about understanding phenomenon from individuals' viewpoints by exploring interaction among people [41]. The hermeneutics approach was used from two main angles in the analysis: (1) the relationships that exist between humans and big data in an organisation; and (2) the interactions that happen between humans in one hand, and on another between humans and big data. Through understanding of the relationships and interactions that happen between: human-to-human; and human-tobig data, the objectives of the study was achieved.

\section{Case Study: Data Analysis}

Based on the objectives of the study as stated in section above, data was collected as discussed in the section above. The participants in the study were coded, for the following reasons: (1) To adhere to research ethics of the university (CPUT); (2) To preserve the identity of the participants; and (3) To respect the policy of the organisation that was used a case in the study. Thus, the code is as follow: participant- 
codename, page\#: line\#. PuInter01, Pg2: 3-5 - this means: participant 1, page 2, line 3 to 5 of the interview transcript.

The data was analysed following the hermeneutics approach from the interpretivist perspective. The hermeneutics approach was used in the analysis from the interpretivist perspective. The analysis focuses on two main areas: (1) The relationships that exist between humans and big data in an organisation; and (2) The interactions that happen between humans in one hand, and on another between humans and big data. This was to gain better understanding of the relationships and interactions that happen between: human-to-human; human-to-big data; and big data-to-big data, in achieving the objectives of the study. The analysis was conducted according to the objectives of the study, which were (1) to determine the factors that influence the selection of BDA in organisations; and (2) to establish criteria for appropriateness of BDA tools in an organisation.

\subsection{The Factors that Influence the Selection of Big Data Analytics in Organisations}

Big data is not all about volume, but defined by its characteristics, which include the Vs, volume, velocity, veracity, variety, and value [1]. The tools that are employed in the analyses of big data are referred to as analytics tools. Some BDA tools/software have the capabilities to process datasets which are employed by organisations for various purposes. There are different types of big data analytics tools, which include diagnostic, descriptive, predictive, and prescriptive [17]. Through the use of big data analytics tools organisations make effective and appropriate strategic decisions.

Big data analytics is on one hand sophisticated. On another hand, the same sophistication makes it complex. Thus, many people including organisation are sometimes confused about the purposes as well as the types of big data analytics. According to the senior manager in the organisation:

We are using Pentaho data integrator and Pentaho business analytics for the analysis of our big data (PuInter01, Pg1: 32-34).

The BDA topic appears to be an overwhelming subject in the organisation, as it focuses on the bigger picture in terms of the terminology that comes with the tools. In the organisation there was a process that was followed in the selection of BDA tools. The process was sequential, meaning one step after the other. The primary components of the process include an understanding and formulation of organisational needs, exploration of available analytics tools, and evaluation of the tools within the context of the organisation. In the evaluation, the components were viewed from the aspects of technical and non-technical factors.

An organisation's goals and mission are a guide to choosing tools that suit its business needs. The selection of analytics tools does not only depend on the business goal, humans' involvement was critical, particularly in the decision-making as well as consideration of the users. Individuals such as business mangers seem to influences the decision in the selection of BDA tools. Nonetheless in the organisation it appears to be person leading the IT unit that agrees and takes ownership of the selecting the tools 
employed, however the tool that is selected has to be aligned with the business objectives. According to one of the participants, a senior architect in the organisation:

The organisation's requirements determine the selection of the tool. The challenge is mostly in formulating requirements, which include processes and events (Pulnter02, Pg6: 20-23).

In the organisation the input of other employees that are using these tools influences the selection of the tools being employed in the organisation. Despite the requirements from the business the staff consider and evaluate the technical and non-technical factors of the tools because they are equipped with knowledge of how the tools work. According to an IT senior manager in the organisation:

This is not a visualization tool it is more of a data analytics tool. It sometimes get restricted by the ability of the user. Whereas some other tools basically aid the users towards achieving their objectives (Pulnter01, Pg3: 1-3).

Despite the existence of numerous number of big data analytics tools, the organisation did choose few that were suitable for its business processes, activities and events. In the organisation the evaluation phase covers a lot of aspects. The aim of the organisation is to have a tool that can put the organisation on the direction of success. It is also to get big data analytics tools that are flexible and scalable. They seem to look at the knowledge they have on the tool itself. There seem to be a lot that the organisation covers in terms of creating an environment that the employees are familiar with.

\subsection{Criteria for Appropriateness of Big Data Analytics Tools in an Organisation}

Criteria is a set of standards and principles purposely for guide decision-making, and measuring scope and boundaries of actions in an activity or environment, the standards and principles are embedded with factors [42]. In the organisation, criteria was formulated, and used in the selection of BDA tools. The criteria consisted of factors, such as cost, supportability, features, and skills required to use and support the tools. Despite a set of criteria, familiarity with a tool was most important. According to one of the participants:

Cost, knowledge of skills are some of the factors that are required in the evaluation of the tools.

We have got to understand our future direction in line with the tool (PuInter01, Pg2: 5-7).

In the organisation the criteria was used as guidelines in selecting a tool that was intended to benefit the organisation from return on investment point of view. This means that the also act as principle, which guided the employees in their focus and actions, and did not allow easy move from one tool to another. According to a senior architect in the organisation:

Some of the tools are very well marketed by the owners and vendors. As a result, without requirements, there is a high possibility of selecting inappropriate tools (PuInter02, Pg3: 14-16).

There were requirements two, business and IT units that formed the criteria, which was enabled by communication. Through the communication between the units including management team, the criteria was defined. The management of both IT and 
business units of the organisation were involved in gathering of the requirement that were used to formulate the criteria. This was primarily because they knew better knowledge about the current and future states of the organisation. Although there was no particular explanations why certain big data analytics tool was selected from the employees that were involved. This is attributed to the fact that the management of the organisation takes ownership of the process and the tool that was selected.

Despite the strengths of the tools that were employed in the organisation that has been used as a case in the study, there are challenges that have been highlighted. The main challenges that the organisation seem to be facing with the tools that were currently employed is about scarcity of skilled personnel, to use and provide technical support. In achieving the organisation' objectives, the current tools requires special skills, a person with an understanding of the functionalities and operations of the tools. One of the participants explains:

Our current tool is focuses more on data specialisation. It is therefore unrestricted to data analysis and management (PuInter01, Pg2: 35-37).

Looking for a tool that would cater for everything is almost impossible. The organisation highlighted a challenge while selecting the appropriate tool from the limitless tools/applications that are available in the market. Without a properly defined requirements and formulation of criteria, there will always be challenges in selecting BDA tools. Also, organisation would change the tools frequently as they get influenced by excitable new functions that the some of the tools present.

Changing the tools from one BDA tools to another takes a lot effort and can be costly. The organisation seem to have a strategy, which can accommodate such situation. In the organisation the change is accepted only when there is a tool that offers better features than the one that is currently in use. Also, the organisational change leans towards goals and objectives.

\section{Findings and Discussion}

Based on the analysis as presented above, four factors were found to be critical in shaping and influencing the selection of BDA tools in an organisation. The factors were revealed based on the understanding of the analysis, which come from subjective reasoning. As shown in Fig. 1, the factors are criteria, business/IT alignment, governance, and skill-sets. The factors are based on organisational vision. The factors are therefore a set of building block, as discussed below.

\subsection{The Role of Criteria}

Criteria is a set of guidelines that are built on principles and standards that can be used to evaluate the BDA tools for organisations [43]. In this study, criteria consist of two main components, which are the business requirements and IT requirements. Business requirements is mostly connected with the goals, mission and objective, which come from the organisation vision. Business requirements work toward paving and setting what the business seeks to achieve. The IT requirements are based on attributes such as 


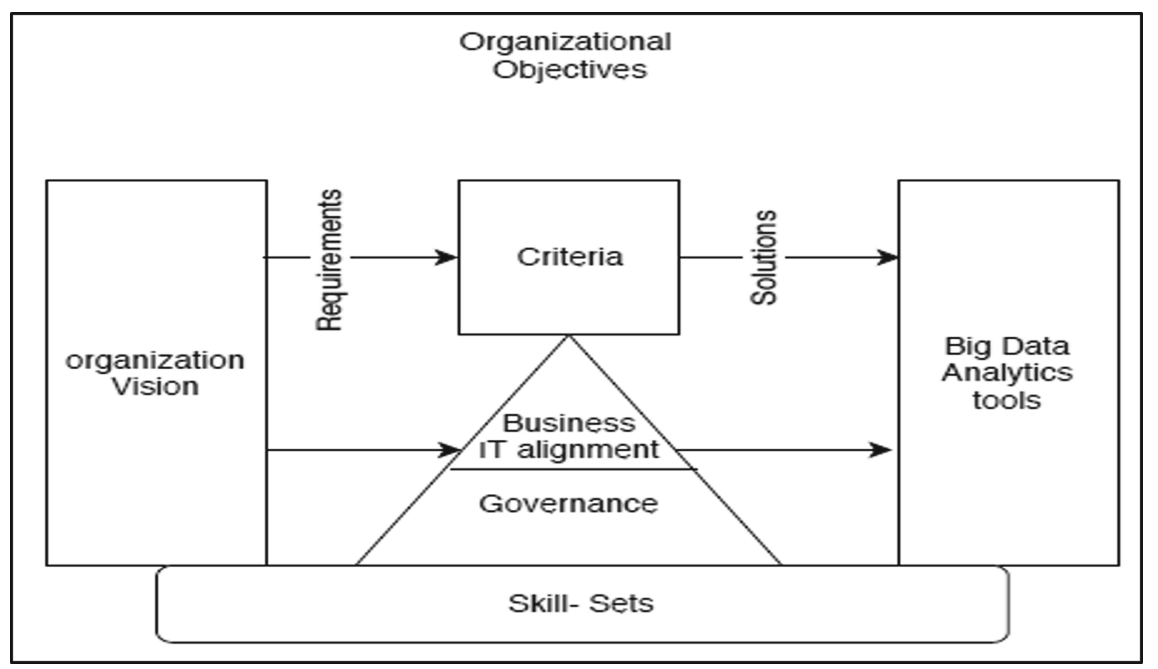

Fig. 1. Building blocks

technology types, co-existence and compatibility, capacity, and flexibility of technologies. The IT requirements seek to enable and support the business requirements toward achieving the objectives of the organisation. This also means IT can be a constraint in that deficiency within the IT will have negative impact on the business requirements.

Based on both business and IT requirements, the set of criteria can be used as a control mechanism for selecting the most appropriate big data analytics tools for organisational purposes. The vital role of the criteria is that the organisation have rich understanding in what they want to do and what will fit the organisation needs. This also means that there is an evaluation process undertaken in the selection of the tools. Another significance factor in creating criteria is that it minimizes the chances of duplicating analytics tools for the same or similar purpose, and it mitigates against risks.

\subsection{Business and IT Alignment}

The concept of Business and IT alignment is not new, it has been explored or applied in various ways. Also, it has been expressed in several terms such as, linkage, integration, and agreement. However, alignment does not refer to being aligned or not aligned, rather it how the relationship needs to be adjusted based on business unforeseen event [44]. Some of the most important and crucial contributors identified in the alignment between business/IT in the selection of BDA tools are communication and uniformity. Communication plays a significance role between the business and IT units in decision making. In addition, the uniformity of how things are done, following processes and policies of an organisation is important.

Lack of alignments between the business and IT units can cause chaos in selecting BDA tools. As a result, working environment can become unstable, and leads to 
deploying applications that cannot serve the organisational purpose. It is clear that lack of alignment between business and IT units have huge implications, such as cost prohibitive, and technology compatibility risks for an organisation in selecting BDA tools.

\subsection{Governance}

Governance consists of standards, principles, and policies [45]. It gives a structural guide to specialists and managers in decision-making. It is also procedural, which gives power to relevant authority to make decisions [46]. Thus, governance can be used to guide the selection of appropriate BDA tools in an organisation. There is means that the selected BDA tools adhere to standards and principles of the organisation.

Selection of the analytics tools is one thing, and its use is another thing. The use of the BDA tools is as critical as the selection, which therefore also require guidance. Governance can be used to guide the use and management of the tools, to avoid technology conflicts and abnormalities. Lack of governance principles in organisation promote poor product quality. Also, it allows employees to avoid or shift accountability and responsibility as they deemed.

\subsection{Skill-Set}

Big data analytics is an emerging concept, particularly in developing countries such as South Africa. As a result, there is scarcity of skill-set in the area of BDA, which affects the slow deployment of the concept in South African organisations. The skill-set play a very critical role in the deployment and use of BDA [47]. The noticeable reasons of the complexity of BDA require data scientist to perform. The machine learning applications designed to analyse big data requires skills of data scientist.

Although it is crucial to have the skill-set, what is even more important is retention of the personnel. Retention allows an organisation to keep their trained and skilled personnel as long as possible. This saves cost of upskilling, which can be very prohibitive, and affect return on investment. Lack of skills lead to incorrectness of data and operations falling apart, which influence decision-making, and ultimately affect business goal negatively.

\section{Conclusion}

This study that was conducted is proposed to assist organisation that wish to deploy and those that have already deployed BDA tools by doing an evaluation of the tools to seek for the tools that suit the organisations goal. In this study organisations will get a better understanding of the process of selecting an appropriate tools using criteria as guide. This study can be of usefulness in organisation that seek to understand the value of having a criteria to evaluate the BDA tool in the market. The research was limited to evaluation of BDA tools. This means that it excludes other activities such as deployment and readiness, as well as the application that are connected to BDA tools. 


\section{References}

1. Gandomi, A., Haider, M.: Beyond the hype: big data concepts, methods, and analytics. Int. J. Inf. Manage. 35(2), 137-144 (2015)

2. Cukier, K., Mayer-Schönberger, V.: Big Data: A Revolution That Will Transform How We Live, Work, and Think. Houghton Mifflin Harcourt, Boston (2013)

3. Katal, A., Wazid, M., Goudar, R.H.: Big data: issues, challenges, tools and good practices. In: 2013 Sixth International Conference on Contemporary Computing (IC3), pp. 404-409. IEEE, August 2013

4. Hofacker, C.F., Malthouse, E.C., Sultan, F.: Big data and consumer behavior: imminent opportunities. J. Consum. Mark. 33(2), 89-97 (2016)

5. Ghazal, A., et al.: BigBench: towards an industry standard benchmark for big data analytics. In: Proceedings of the 2013 ACM SIGMOD International Conference on Management of Data, pp. 1197-1208. ACM, June 2013

6. Demchenko, Y., De Laat, C., Membrey, P.: Defining architecture components of the Big Data Ecosystem. In: 2014 International Conference on Collaboration Technologies and Systems (CTS), pp. 104-112. IEEE (2014)

7. Mgudlwa, S., Iyamu, T.: Integration of social media with healthcare big data for improved service delivery. S. Afr. J. Inf. Manag. 20(1), 1-8 (2018)

8. De Mauro, A., Greco, M., Grimaldi, M.: What is big data? A consensual definition and a review of key research topics. In: AIP Conference Proceedings, vol. 1644, no. 1, pp. 97-104, February 2015

9. Veiga, J., Expósito, R.R., Pardo, X.C., Taboada, G.L., Tourifio, J.: Performance evaluation of big data frameworks for large-scale data analytics. In: 2016 IEEE International Conference on Big Data (Big Data), pp. 424-431. IEEE, December 2016

10. Suthaharan, S.: Big data classification: problems and challenges in network intrusion prediction with machine learning. Perform. Eval. Rev. 41(4), 70-73 (2014)

11. Sivarajah, U., Kamal, M.M., Irani, Z., Weerakkody, V.: Critical analysis of Big Data challenges and analytical methods. J. Bus. Res. 70, 263-286 (2017)

12. George, G., Haas, M.R., Pentland, A.: Big data and management. Acad. Manag. J. 57(2), 321-326 (2014)

13. Barton, D., Court, D.: Making advanced analytics work for you. Harvard Bus. Rev. 90(10), 78-83 (2012)

14. Delone, W.H., McLean, E.R.: The DeLone and McLean model of information systems success: a ten-year update. J. Manage. Inf. Syst. 19(4), 9-30 (2003)

15. Andargoli, A.E., Scheepers, H., Rajendran, D., Sohal, A.: Health information systems evaluation frameworks: a systematic review. Int. J. Med. Informatics 97, 195-209 (2017)

16. Agostinho, C., et al.: Towards a sustainable interoperability in networked enterprise information systems: trends of knowledge and model-driven technology. Comput. Ind. 79, 64-76 (2016)

17. Iyamu, T.: A multilevel approach to big data analysis using analytic tools and actor network theory. S. Afr. J. Inf. Manag. 20(1), 1-9 (2018)

18. Davenport, T.H., Dyché, J.: Big data in big companies. International Institute for Analytics, no. 3 (2013)

19. Daniel, B.: Big Data and analytics in higher education: opportunities and challenges. Br. J. Educ. Technol. 46(5), 904-920 (2015)

20. Wamba, S.F., Akter, S., Edwards, A., Chopin, G., Gnanzou, D.: How 'big data' can make big impact: findings from a systematic review and a longitudinal case study. Int. J. Prod. Econ. 165, 234-246 (2015) 
21. Wolfert, S., Ge, L., Verdouw, C., Bogaardt, M.J.: Big data in smart farming-a review. Agric. Syst. 153, 69-80 (2017)

22. Najafabadi, M.M., Villanustre, F., Khoshgoftaar, T.M., Seliya, N., Wald, R., Muharemagic, E.: Deep learning applications and challenges in big data analytics. J. Big Data 2(1), 1 (2015). https://doi.org/10.1186/s40537-014-0007-7

23. Grover, V., Chiang, R.H., Liang, T.P., Zhang, D.: Creating strategic business value from big data analytics: a research framework. J. Manage. Inf. Syst. 35(2), 388-423 (2018)

24. Günther, W.A., Mehrizi, M.H.R., Huysman, M., Feldberg, F.: Debating big data: a literature review on realizing value from big data. J. Strateg. Inf. Syst. 26(3), 191-209 (2017)

25. Erevelles, S., Fukawa, N., Swayne, L.: Big Data consumer analytics and the transformation of marketing. J. Bus. Res. 69(2), 897-904 (2016)

26. Ji-fan Ren, S., Fosso Wamba, S., Akter, S., Dubey, R., Childe, S.J.: Modelling quality dynamics, business value and firm performance in a big data analytics environment. Int. J. Prod. Res. 55(17), 5011-5026 (2017)

27. Wang, Y., Kung, L., Byrd, T.A.: Big data analytics: understanding its capabilities and potential benefits for healthcare organisations. Technol. Forecast. Soc. Chang. 126, 3-13 (2018)

28. Alharthi, A., Krotov, V., Bowman, M.: Addressing barriers to big data. Bus. Horiz. 60(3), 285-292 (2017)

29. Pearlson, K.E., Saunders, C.S., Galletta, D.F.: Managing and Using Information Systems, Binder Ready Version: A Strategic Approach. Wiley, Hoboken (2016)

30. Laudon, K.C., Laudon, J.P.: Management Information System. Pearson Education India, New York (2016)

31. Hallikainen, P., Chen, L.: A holistic framework on information systems evaluation with a case analysis. Lead. Issues ICT Eval. 9, 57-64 (2006)

32. Irani, Z., Love, P.E.: Developing a frame of reference for ex-ante IT/IS investment evaluation. Eur. J. Inf. Syst. 11(1), 74-82 (2002)

33. Iyamu, T.: Collecting qualitative data for information systems studies: the reality in practice. Educ. Inf. Technol. 23, 2249-2264 (2018). https://doi.org/10.1007/s10639-018-9718-2

34. Kumar, R.: Research Methodology: A Step-by-Step Guide for Beginners. Sage Publications Limited, Thousand Oaks (2019)

35. Walliman, N.: Research Methods: The Basics. Routledge, New York (2017)

36. Yin, R.K.: Case Study Research and Applications: Design and Methods. Sage Press, Los Angeles (2017)

37. Neuman, W.L.: Social Research Methods: Qualitative and Qualitative Approaches. Allyn and Bocon, Boston (2000)

38. Butler, T.: Towards a hermeneutic method for interpretive research in information systems. J. Inf. Technol. 13(4), 285-300 (1998). https://doi.org/10.1057/jit.1998.7

39. Boell, S.K., Cecez-Kecmanovic, D.: Literature reviews and the hermeneutic circle. Aust. Acad. Res. Libr. 41(2), 129-144 (2010)

40. Myers, M.D., Avison, D.: An introduction to qualitative research in information systems. Qual. Res. Inf. Syst. 4, 3-12 (2002)

41. Scotland, J.: Exploring the philosophical underpinnings of research: relating ontology and epistemology to the methodology and methods of the scientific, interpretive, and critical research paradigms. Engl. Lang. Teach. 5(9), 9-16 (2012)

42. Etzioni, A.: Mixed-scanning: a "third" approach to decision-making. Public Adm. Rev. 27, 385-392 (1967)

43. Cai, L., Zhu, Y.: The challenges of data quality and data quality assessment in the big data era. Data Sci. J. 14, 2 (2015) 
44. Luftman, J., Lyytinen, K., Zvi, T.B.: Enhancing the measurement of information technology (IT) business alignment and its influence on company performance. J. Inf. Technol. 32(1), 26-46 (2017)

45. Shaanika, I., Iyamu, T.: Developing the enterprise architecture for the Namibian government. Electron. J. Inf. Syst. Dev. Ctries. 84(3), e12028 (2018)

46. Bennett, B., Bradbury, M., Prangnell, H.: Rules, principles and judgments in accounting standards. Abacus 42(2), 189-204 (2006)

47. Ahmed, E., et al.: The role of big data analytics in Internet of Things. Comput. Netw. 129(2), 459-471 (2017) 